\section{AB0356 ASSOCIATION BETWEEN CARDIOVASCULAR RISK FACTORS AND CAROTID INTIMA-MEDIA THICKNESS IN PATIENTS WITH RHEUMATOID ARTHRITIS}

R. González Mazarío ${ }^{1}$, J.J. Fragio Gil ${ }^{1}$, J. Ivorra Cortes $^{1}$, C.M. Feced Olmos ${ }^{1}$, F.M. Ortiz-Sanjuan ${ }^{1}$, E. Grau Garcia ${ }^{1}$, E. Labrador Sánchez ${ }^{1}$, S. Huerta Barberá $^{2}$, K. Arévalo Ruales ${ }^{1}$, R. Negueroles Albuixech ${ }^{1}$, I. Martínez Cordellat ${ }^{1}$, I. Chalmeta Verdejo ${ }^{1}$, L. Gonzalez Puig ${ }^{1}$, C. Alcañiz Escandell ${ }^{1}$, C. Nájera Herranz ${ }^{1}$, I. Cánovas Olmos ${ }^{1}$, E. Vicens Bernabeu ${ }^{1}$, J.E. Oller Rodriguez ${ }^{1}$, V. Fornés Ferrer ${ }^{3}$, J.A. Román Ivorra ${ }^{1,2},{ }^{1}$ Rheumatology Department, HUP la Fe; ${ }^{2}$ Medical School, UCV; ${ }^{3}$ Biostatistic Unit, IIS la Fe, Valencia, Spain

Background: Rheumatoid arthritis (RA) is a chronic inflammatory disease which affects $0.5 \%$ of adults, especially women. This disorder is associated with increased morbidity and mortality due to atherosclerotic cardiovascular diseases. In addition to classical cardiovascular risk factors, inflammation plays a key role in this fact. Intima-media thickness (IMT) measured by carotid ultrasound is currently used to detect the presence of atherosclerotic disease and its value could be a predictor of subclinical cardiovascular disease.

Objectives: To study cardiovascular risk factors, disease activity and carotid IMT in a RA patients series.

Methods: Cross-sectional observational study of patients diagnosed with RA according to ACR/EULAR 2010 criteria. Patients with age under 75 years old and up of 5 years of disease evolution were included. Cardiovascular established disease patients were excluded. During a unique visit, patients underwent anamnesis, physical examination, laboratory test, electrocardiogram, chest X-ray and carotid ultrasound with Esaote-MyLabClassC equipment. Statistical analyses were performed using software $\mathrm{R}$ (version 3.3.2).

Results: A total of 31 patients $(57.1 \pm 9.7$ years, $83.6 \%$ female, with $19.2 \pm 11.2$ years of average disease course) were included. In relation to the classic cardiovascular risk factors, $19.4 \%$ were active smokers, $41.9 \%$ hypertensives and $45.2 \%$ had hypolipidemic treatment $(85.7 \%$ with a statin), three of the patients were diabetic $(9.7 \%)$. All patients were treated with monotherapy or combination therapy and $41.9 \%$ were also given glucocorticoid at low doses during the last 6 months. The median DAS28-VSG was $2.49\left(1^{\circ} \mathrm{Q}=1.6 ; 3^{\circ} \mathrm{Q}=3.9\right)$, with an average $\mathrm{HAQ}$ of $0.88 \pm 0.68$. As for extra-articular manifestations, $45.2 \%$ had xerophthalmia, $29 \%$ xerostomia, and $19.4 \%$ had rheumatoid nodules. The median total cholesterol was $195 \mathrm{mg} / \mathrm{dL}$ (174-221), and LDL of $116 \mathrm{mg} / \mathrm{dL}(96.5-138)$. The mean of the right carotid IMT was $576.13 \pm 118.78 \mathrm{~mm}$ and the carotid left IMT was $616.32 \pm 134.31 \mathrm{~mm}$, resulting in 12 determinations higher values than expected to their age and sex provided by the ultrasound developer (38.7\%). Using the SCORE table (modified by EULAR), only 5 patients $(16.1 \%$ ) had moderate-to -high cardiovascular risk. Statistical analysis showed a significative association between an increased IMT with tobacco consumption (classic cardiovascular risk factor) $(p=0.028)$ and the modified SCORE $(p=0.04)$. Neither years of evolution of disease nor the analytical biomarkers showed a significant association.

Conclusions: Our study shows that in patients with good disease control data, classic cardiovascular risk factors are related to increased carotid intima-media thickness. However, these factors may underestimate overall cardiovascular risk over other measures of subclinical cardiovascular disease, such as carotid IMT.

Disclosure of Interest: None declared

DOI: 10.1136/annrheumdis-2017-eular.5868

\section{AB0357 SEXUALITY IN WOMEN WITH RHEUMATOID ARTHRITIS - RESULTS OF A SURVEY}

R. Puchner ${ }^{1}$, J. Sautner ${ }^{2}$, J. Gruber ${ }^{3}$, A. Trenkler ${ }^{4}$, E. Bragagna ${ }^{5}$, G. Eberl ${ }^{6}$ A. Alkin ${ }^{7}, \mathrm{H}$. Pieringer ${ }^{8} .{ }^{1}$ Rheumatologist in private practice Wels, Wels; ${ }^{2}$ Lower Austrian State Hospital, Stockerau, Stockerau; ${ }^{3}$ Medical University of Innsbruck, Innsbruck: ${ }^{4}$ Elisabethinen Hospital Linz, Linz: ${ }^{5}$ Specialist in Sexual Medicine in private practice Vienna, Vienna; ${ }^{6}$ Klinikum Malcherhof Baden, Baden bei Wien; ${ }^{7}$ Centre of Excellence in Medicine Linz; ${ }^{8}$ 2nd Department of Medicine, General Hospital Linz and Faculty of Medicine, Johannes Kepler University Linz, Linz, Austria

Background: Diseases such as rheumatoid arthritis (RA) are distinguished by their chronic and progressive characteristics; they may lead to premature loss of joint function and constitute major social, economic and health burdens. Rheumatic diseases may affect all aspects of life including patients' sexuality. Objectives: The objective of the study was to evaluate the impact of RA on women's sexuality regarding sexual motivation, activity, and satisfaction and to assess the correlation of disease related physical impairment within sexual functioning.

Methods: A group of rheumatologists, a sociologist and a specialist in sexual medicine initiated a substantial survey, including standardised questionnaires. The items asked were assessments of disease activity with the Clinical Disease Activity Index (CDAl) and measurements of illness and medically induced changes in sexual functioning with the Changes in Sexual Functioning Questionnaire-short form (CSFQ-14). Levels of depression were evaluated with the Beck Depression Inventory FastScreen (BDI FastScreen) and to establish disability the Health assessment questionnaire ( $\mathrm{HAQ}$ ) was used. Further questions were concerning demographic and health related data such as comorbidities, medication, alcohol and smoking habits.

Results: 319 questionnaires were distributed to RA-patients and 319 to healthy controls (HCOs). 235 questionnaires from patients $(73,7 \%)$ and $180 \mathrm{HCO}-$ questionnaires $(58,8 \%)$ were sent back.

Women with RA had a significantly lower CSRQ Score than HCOs. $48 \%$ of the patients had a total CSFQ score of $<41$, which is defined as an indicator of sexual dysfunction. However, only $14 \%$ of the healthy respondents scored similarly. $29.3 \%$ of the surveyed patients were in remission, $45.1 \%$ in low disease activity, $18.9 \%$ in a moderate disease activity and $6.8 \%$ in high disease activity. There was no relationship between CDAI and CSFQ.

Age and level of education were the most important demographic parameters connected with sexual dysfunction. There was also a moderate and significant relationship between depression and sexual dysfunction.

A significant correlation between the HAQ index and the level of sexual dysfunction was to be observed.

Conclusions: Due to the lack of substantive surveys in this field, we tried to undertake a comprehensive study covering sexual dysfunction in women with RA. The study shows that RA has a significant effect on the sexuality of women, compared to healthy individuals.

Disclosure of Interest: R. Puchner Grant/research support from: unrestricted industrial grant Pfizer Austria WI205954, J. Sautner: None declared, J. Gruber: None declared, A. Trenkler: None declared, E. Bragagna: None declared, G. Eberl: None declared, A. Alkin: None declared, H. Pieringer: None declared DOI: 10.1136/annrheumdis-2017-eular.3437

\section{AB0358 PATIENTS WITH EARLY RHEUMATOID ARTHRITIS HAVE INCREASED CARDIOVASCULAR RISK AT THE TIME OF DIAGNOSIS}

R. Davies ${ }^{1}$, C.R. Thompson ${ }^{1}$, H.S. Jin ${ }^{1}$, E.A. Ellins ${ }^{2}$, J.P. Halcox ${ }^{2}$, A.S. Williams ${ }^{1}$, E.H.S. Choy ${ }^{1} .{ }^{1}$ CREATE centre, Institute of Infection and Immunity, Cardiff University, Cardiff; ${ }^{2}$ Institute of Life Sciences, Swansea University Medical School, Swansea, United Kingdom

Background: Cardiovascular (CV) mortality in patients with rheumatoid arthritis (RA) is up to $50 \%$ higher than the general population. Whilst traditional $\mathrm{CV}$ risk factors such as smoking, diabetes and hypertension contribute to this increased mortality in RA, they do not fully explain the increase in risk. The British Society for Rheumatology, National Institute for Health and Clinical Excellence and European League Against Rheumatism (EULAR) recommend annual assessment of CV risk in RA patients. Furthermore, EULAR recommends multiplying such traditional CV risk scores by 1.5 for RA patients who meet two of three criteria consisting of (1) disease duration $>10$ years, (2) positive rheumatoid factor or anti-cyclic citrullinated peptide (anti-CCP) serology, (3) presence of severe extra-articular manifestation, to account for the unexplained increased $\mathrm{CV}$ risk in RA.

Objectives: This study assessed CV risk by QRISK2 score and used carotid ultrasound to determine cardiovascular risk and prevalence of subclinical atherosclerosis at the time of diagnosis of RA.

Methods: Patients $\geq 18$ years-old with early RA, defined by ACR/EULAR 2010 criteria and diagnosis of RA $<6$ months were recruited from The University Hospital of Wales, Cardiff. Exclusion criteria included definite other autoimmune or inflammatory rheumatic disease, ACR Classification of Functional Status stage IV, previous history of CV disease and diabetes mellitus. Demographic details were collected, blood pressure, body mass index, ESR, CRP and lipid profile were measured and QRISK2 was calculated. Carotid ultrasound was performed and mean carotid intima media thickness (CIMT) and presence of plaque were measured. The study was approved by Research Ethics Committee for Wales (11/WA/0326).

Results: 40 patients, 10 males and 30 females with early RA were recruited. Mean age was $55.7 \pm 14.8$ years. Rheumatoid factor and anti-CCP antibodies were positive in $62 \%$ and $80 \%$ of patients respectively. Mean BMI was $27.2 \pm 5.9$. Twenty-nine percent were current smokers. Mean DAS28 was $3.8 \pm 1.3$. According to the QRISK2, $54 \%$ of patients had $>10 \%$ risk of $\mathrm{CV}$ disease over 10 years. Carotid ultrasound was conducted in 35 patients. Mean CIMT was $0.71 \pm 0.19 \mathrm{~mm}$. 10 patients $(29 \%)$ had carotid plaques. Fourteen patients $(40 \%)$ had either plaque or CIMT $>0.9 \mathrm{~mm}$, both considered markers of high CV risk. These patients were termed "ultrasound positive" patients. The sensitivity and specificity of the QRISK2 to predict US positive patients was $82 \%$ and $56 \%$ respectively. The positive predictive value of the QRISK2 was $63 \%$ and the negative predictive value of the QRISK2 was $88 \%$. No patients met $>1$ criteria for EULAR adjustment of risk as all patients had early RA and none had severe extra-articular manifestations.

Conclusions: Many patients with early RA have significant CV disease at the time of diagnosis. This suggests subclinical CV disease may be developing before patients become symptomatic. More than half of the patients with early RA fulfil current NICE guidelines for starting lipid-lowering therapy, although of these, over one-third had no subclinical disease on carotid ultrasound. There is scope to improve the sensitivity and specificity of the QRISK2 calculation in RA patients, perhaps with a biomarker

Acknowledgements: This work was funded by Arthritis Research UK, grant number 20760

Disclosure of Interest: None declared

DOI: 10.1136/annrheumdis-2017-eular.3240 